\title{
Gender inequality in sports press coverage: Based on the example of Gazeta Wyborcza (2010-2013)
}

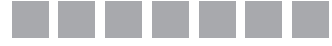 \\ Zuzanna Mazur \\ Natalia Organista \\ Zbigniew Dziubiński
}

UNIVERSITY OF PHYSICAL EDUCATION IN WARSAW, POLAND

DOI: 10.19195/1899-5101.11.1(20).6

\begin{abstract}
The aim of the study was to analyze the press coverage of sports published in the largest Polish daily newspaper, Gazeta Wyborcza, in terms of gender inequality. The content (both qualitative and quantitative) analysis method was used. In the study, the number of articles on women and men was examined, with the qualitative sections consisting of an analysis of gender stereotypes appearing in these articles. The results demonstrated the underrepresentation of women in the examined sports press coverage. The qualitative analysis showed that articles dealing with women's sports included gender stereotypes. The articles focused on the physical appearance of women or on their non-sports lives. Infantilizing and marginalizing comments were also present. The study revealed the gender-dependent nature of the press coverage of sports in Poland.
\end{abstract}

KEYWORDS: gender, content analysis, press coverage, gender stereotypes, Gazeta Wyborcza, femininity.

\section{INTRODUCTION}

In recent years, much attention has been paid to studies concerning the way of constructing and reflecting both femininity and masculinity in sports. The impact of the media on sustaining these patterns created in sports has also been analyzed. The issue has been thoroughly examined, due to the power of the media in terms of giving meaning to and reproduction of specific cultural content. Although today a strong emphasis is put on nuancing the impact of the media on the audience, a critical paradigm in the study on communication has its grounding in the belief in such a power of the media.

In the study, the theory of gender relations structures by Connell has been applied (Connell, 1998; Connell, 2013). The researcher believes that in society, various types of hierarchical masculinity and femininity structures, based on power rela- 
tions, are constructed. The most important item of note is that hegemonic masculinity retains a dominant position in society. Masculinity and femininity are always interrelated, but hegemonic masculinity remains at the top of the hierarchy. It is characterized by high social status, physical fitness, and heterosexuality (Connell, 2001). In Connell's theory, physicality is seen as the basic source of constructing masculinity and femininity. Sport is the sphere of social life where gender differences can be most easily observed. This made it possible to notice that sport maintains the traditional gender hierarchy. Strength, endurance, and perfect training nurture the traditional perception of masculinity. In turn, emphasized femininity is supported by an adherence to the cultural ideals of beauty, passivity, subordination, and empathy. Due to the fact that femininity in sport is judged mainly based on external appearance, it is marginalized and trivialized. Therefore, the images of women in sports are subject to conflicting cultural evaluations - the strength, endurance, and physical fitness required for success in sports do not fit into the cultural ideals of emphasized femininity. For this reason, Messner (1998) states that images of women in sports media may have a subversive influence on patriarchal culture.

Relational connection between masculinity and femininity makes the sport reflect the traditional hierarchy of sexes. This is noticeable not only in the way the media speak of women's sport and men's sport, but also in perceiving the work of female coaches, sport journalists or sport activists (Jakubowska, 2013, pp. 331-344, 395). The belief that sport is a male thing makes femininity marginalized and considered to be improper for the world of sports. According to Messner and Sabo, sports have been, and continue to be, one of the most masculine social institutions, and team sports are seen as the "core" of masculinity (Messner, 1992; Messner \& Sabo, 1994). Sport is considered to be a natural activity for boys and men, one of the most basic forms of spending free time (Whiston, 1989). Girls or women are accepted in sport as far as they do disciplines deemed feminine and remain feminine in traditional terms.

The underrepresentation of women in sport media coverage - review of quantitative analyses

A different approach to women's and men's sports can be observed both in quantitative and qualitative studies. Quantitative studies demonstrated the great underrepresentation of women's sports. The longitudinal study by Messner and colleagues has shown that in 2014 only 3.2 per cent of the airtime (local Los Angeles network affiliates) for sports news was devoted to information about women's sports (Cooky et al., 2013). During 25 years of research, only in 2009 it provided lower values (Cooky et al., 2015). Other studies of televised coverage confirm the results obtained by the researchers (Billings \& Turner, 2013; Billings \& Young, 2015; Martin et al., 2016). Analyses of the printed media also confirm these results (Harris \& Clayton, 2002; Bishop, 2003; Vincent, 2004). Initially, press research also 
demonstrated underrepresentation of women. More recent studies, however, point to the media coverage which is proportional to the number of sportswomen (Capranica et al., 2005; King, 2007; Vincent et al., 2002). As Kane comments on the obtained results of the research, it is surprising since 40 per cent of sportspeople in the USA are women. According to the researcher, the obtained results prove not so much ignoring women in the media but rather creating false narration that women are either not interested in sport or not talented enough (Kane, 2013, p. 233). In Poland, an international research project carried out for a duration of two months in three daily newspapers (The International Sport Press Survey - ISPS) demonstrated that 85 per cent of the sports press coverage concerned men's sports, while only 9 per cent was focused on women's sports (Jakubowska, 2013).

Thus, it can be concluded that the diagnosis offered more than thirty years ago of the symbolic annihilation of women in the media is still accurate (Tuchman, 1979). Only during the Olympic Games can women expect to be the subject of more media coverage. However, this is due to the fact the women are representing a given country, and not to an appreciation of femininity in sports (Vincent et al., 2002; von der Lippe, 2002; Billings et al., 2008). However, during the Olympic Games female athletes cannot count on receiving an equal amount of media coverage, as they are often presented in a different manner. As Billings concludes, what and how will be shown is determined by gender category (Angelini, MacArthur \& Billings, 2012). O'Neill and Mulready (2014) also demonstrated that after the Olympic Games, media coverage of women's sports returns to the pre-Olympic number/ amount.

In quantitative analyses of sports coverage in the media, attention is often paid to those sports that are most frequently discussed in newspapers, radio, or on TV. The division of sports disciplines into those stereotypically associated with femininity (female appropriate) and those that are considered inappropriate for women (female inappropriate) that is a functioning component of societies is stressed (Koivula, 2001; Riemer \& Visio, 2003). The practice of sports by women is approved as long as the sports require a slim figure, graceful movements, and a sense of rhythm; these mostly include individual sports, such as artistic gymnastics, figure skating, or dancing. Sports in which great physical strength is required, those which require endurance and aggression, are not generally perceived as female appropriate. They mostly include team sports - contact and collision ones. Such a division reinforces essentialist assumptions about gender. Also, the practice of journalism is characterized by convictions on the division of sports into female and male disciplines (Cronk \& Theberge, 1994).

The masculinization of editors or commentators within sports journalism can be highlighted as one of the causes for the different presentation of women and men in the media. It is estimated that women account for 10 per cent of all journalists in sports. As the report Gender in Televised Sports claims, in 2009 men accounted for 99.5 per cent of the total number of commentators in KNBC Sports News. In the 
other channel, SportsCenter, male commentators constituted 89 per cent (Messner \& Cooky, 2010, pp. 20-21). Studies carried out by Polish television demonstrate that men are the main presenters and commentators of sporting events (Kluczyńska, 2010). In the press, a predominance of men in sports newsrooms is also observed. Among the authors of the articles analyzed in the context of ISPS 2011, more than 90 per cent were men. The small number of female journalists in sports strengthens the belief that sports are a male endeavor. Another result is that there is a lack of people in the media to speak up about issues specific to women, portraying their experience and perspectives (Kian \& Hardin, 2009). The consequence of such a state of affairs is that there is no one in the media to remind of the issues specific to women, show their experience and their perspective. It is essential because, as the research by Kian and Hardin showed, sex of the journalist influences the way women's sport is portrayed (Kian \& Hardin, 2009). Men would more frequently consolidate gender stereotypes when describing sportswomen. They would also less frequently write about women's sport compared to women. Although not all research shows that employing more female journalists would increase coverage of women's sport, this fact should not be linked with the reluctance of female journalists to women's sport but with their fear of being accused of "favoring" sportswomen and unwillingness of publishers to present women's sport (Hardin \& Shain, 2005; Kian, 2007). The study by Gee and Leberman (2011) demonstrated that for media coverage on women's sports to be approved, it must meet more stringent criteria than men's sports.

The underrepresentation of women in the media - review of qualitative analyses

Wensing and Bruce (2003), by presenting a synthesis of the qualitative investigations on the media coverage of women's sports carried out up until that point, presented five techniques through which women's sports are characterized. Firstly, a given event is emphasized as a women's sport. This shows that men's sports remain as a type of model to which women's rivalries are related. It implies that women's sports are somehow inferior. The second principle is that the beauty and heterosexuality of female athletes are emphasized. The descriptions of female athletes in the media are focused on their physical appearance and sexuality rather than their athleticism or other characteristics responsible for their sporting success. This results in the fact that descriptions of women are unified, but also that the position of women in sports is based upon their being different (von der Lippe, 2002; Jakubowska, 2013). A typical strategy to attract viewers to a given women's sport is to focus on the physical appearance of athletes. For this reason, some federations (FIVB, AIBA, BWF) have tried to push through regulations concerning appropriate attire for female athletes (Sailors, Teetzel \& Weaving, 2012; Ingen \& Kovacs, 2012). Female athletes are also portrayed differently in photo media (Pedersen, 2002). In view of the adopted assumption that the greatest asset of female athletes in sport is their physical appearance, they constantly negotiate their image in order to achieve a balance between athleticism and attractive physical 
appearance (Bishop, 2003; Sherry et al., 2015). Studies on the reception of the sexualized media images of women in sports showed that recipients were induced to make instrumental and objectifying comments, and that these images cannot serve as a basis for the improvement of the reception of femininity in society (Knight \& Giuliano, 2001; Daniels \& Wartena, 2011).

Moreover, female athletes are often presented in non-sports contexts. On the one hand, they are portrayed as someone's partner or mother, and on the other hand their family relationships are described. Daddario (1994) pointed out that an emphasis is often put on the role of female athletes as daughters, stressing their dependence on others. These descriptions show that sports are not the most important activity for women while also reinforcing the belief that true femininity is not based on a woman's career, but instead on their family life. In turn, highlighting female athletes' relationships with their parents or coaches emphasizes their dependence or subordination.

Bruce and Wensing also focused on the infantilization of female athletes through the ways their work is commented on. Language sexism is manifested by calling them by their first names or by using diminutives (Wachs, 2006, pp. 43-54). Such a practice also reduces women's status to that of a child or teenager (Ducan et al., 1994). Female athletes are often described in a negative way as well: as weak and emotional, and thus responsible for their failures (Vincent, 2000). Surely, also men's failures in sport are noticed, however much more often such failures are compensated with the words of appreciation (Cooky et al., 2015). Male athletes are more often depicted as national heroes and sport icons in their disciplines. Females are frequently compared to their male counterparts. This gives the impression that women's sports are secondary and insignificant compared to men's competition.

\section{METHODS}

The primary objective of the study is to determine how much space in newspapers is granted to press communications relating to female and male athletics, as well as to examine the quality of such coverage. The research methods applied were qualitative and quantitative content analysis. The daily Gazeta Wyborcza (GW), as the largest and most opinion-forming newspaper in the country, was selected for the study. Given that the media shape opinions, norms, and values, the selection of a daily newspaper that has the greatest impact on readers was important to the study. The study covered the years 2010-2013, so that the analysis could cover both the Olympic Games (Vancouver 2010, London 2012) and non-Olympic periods due to the difference in the number of articles about women's sports described in many studies. The articles for analysis were selected by a systematic random sampling. Every second week of each month was taken into account (issues from Monday to Saturday). The analysis included articles longer than one hundred words; shorter articles, usually titled "in brief," were only summary reports on recent sports results. More- 
over, columns have not been included in the study, as they only presented the opinions of their authors and did not meet the standards of objectivity that other sports news did. The analysis did not include articles concerning sports that were not directly linked to competitions held in sports arenas, e.g., those relating to the construction of stadiums, the economic potential of sports, etc. Such articles were defined as "neutral." The analyzed articles can be found in the sports columns of GW or in Monday's Sports Extra supplements. A total number of 2,997 articles were analyzed.

A coding sheet was created for coding the results of the analysis. The articles were coded on the basis of their length (number of words), author's sex, and sports discipline and type: individual or team. In the second part of the tool designed for qualitative analysis, five categories of coding were delineated based on the techniques indicated by Wensing and Bruce (2003): appearance and sexuality of athletes (emphasizing their beauty, clothing, or heterosexuality by highlighting their status as a wife, mother, or girlfriend, etc.), emphasizing the stereotypical versions of femininity and masculinity (describing women as emotionally fragile and subordinate, referring to roles and activities outside of sports (the roles of a mother, daughter, wife), language and comments (infantilizing - reducing the athletes to the role of teenagers and children). The last category of coding was the way that successes and failures were described (a focus in the articles on weak performances, or the failures or successes of athletes; the method of explaining failures and victories).

Before the main study, a pilot study was also conducted by researchers in order to test inter-coder reliability. 400 articles were examined, representing 13.3 per cent of the study sample. From the pilot study, researchers were able to achieve 96 per cent reliability in their analyses. The remaining part of the study sample has been randomly assigned to each of the researchers. Each article has been analyzed twice.

\section{RESULTS}

\section{Quantitative analysis}

Out of the 2,997 articles analyzed between 2010 and 2013, only 387 related to women's sports. In subsequent years, the percentage of articles on female sports did not exceed 15.3 per cent (Table 1).

There were months in which only one article on women's sports was published (November 2013, June 2012). To compare, in the same period 37 and 33 articles about male sports were written, respectively. The characteristics of the sports disciplines described in the press communications also differ when analyzed from the perspective of gender. In the articles concerning men, coverage dealing with team sports prevails. In the articles about women's sports, reports on individual sports dominate. This is in accordance with the belief that women's sports are mostly individual ones, and sports for men mainly include team sports (Riemer \& Visio, 
Table 1. Quantitative analysis of press coverage in GW in terms of gender (2010-2013) (in percent)

\begin{tabular}{|l|c|c|c|c|c|c|c|c|}
\hline \multirow{2}{*}{} & \multicolumn{2}{|c|}{2010} & \multicolumn{2}{c|}{2011} & \multicolumn{2}{c|}{2012} & \multicolumn{2}{c|}{2013} \\
\cline { 2 - 9 } & Men & Women & Men & Women & Men & Women & Men & Women \\
\hline $\begin{array}{l}\text { Articles } \\
\text { (\% of all } \\
\text { articles) }\end{array}$ & $\begin{array}{c}87 \\
\mathrm{~N}=893\end{array}$ & $\begin{array}{c}11 \\
\mathrm{~N}=117\end{array}$ & $\begin{array}{c}86 \\
\mathrm{~N}=732\end{array}$ & $\begin{array}{c}11 \\
\mathrm{~N}=94\end{array}$ & $\begin{array}{c}81 \\
\mathrm{~N}=514\end{array}$ & $\begin{array}{c}15 \\
\mathrm{~N}=97\end{array}$ & $\begin{array}{c}81 \\
\mathrm{~N}=471\end{array}$ & $\begin{array}{c}14 \\
\mathrm{~N}=79\end{array}$ \\
\hline $\begin{array}{l}\text { Articles longer } \\
\text { than 550 words }\end{array}$ & 34 & 30 & 39 & 43 & 50 & 48 & 21 & 30 \\
\hline $\begin{array}{l}\text { Articles of 200 } \\
\text { to 550 words }\end{array}$ & 57 & 59 & 49 & 52 & 45 & 42 & 68 & 52 \\
\hline $\begin{array}{l}\text { Articles shorter } \\
\text { than 200 words }\end{array}$ & 9 & 11 & 12 & 5 & 5 & 10 & 11 & 18 \\
\hline
\end{tabular}

Source: Authors.

2003; Koivula, 2001). Over 50 per cent of all articles concerning men dealt with rivalries in soccer. In 2013, the number of articles on soccer reached almost 60 per cent. This shows that soccer still remains the institutional core of sports in Europe and a bastion of masculinity (Giulianotti, 1999).

The characteristics of media coverage concerning women seem to be different. In addition to the significant underrepresentation of women's sports on the pages of GW (12.5 per cent), it can be noted that individual sports were mostly selected for coverage (Figure 1).

The notion that female athletes need to achieve superior results and be world superstars in their sports disciplines in order to reach the headlines was also con-

Figure 1. The most commonly selected sport disciplines in women's sport for coverage in GW (2010-2013) (in percent)

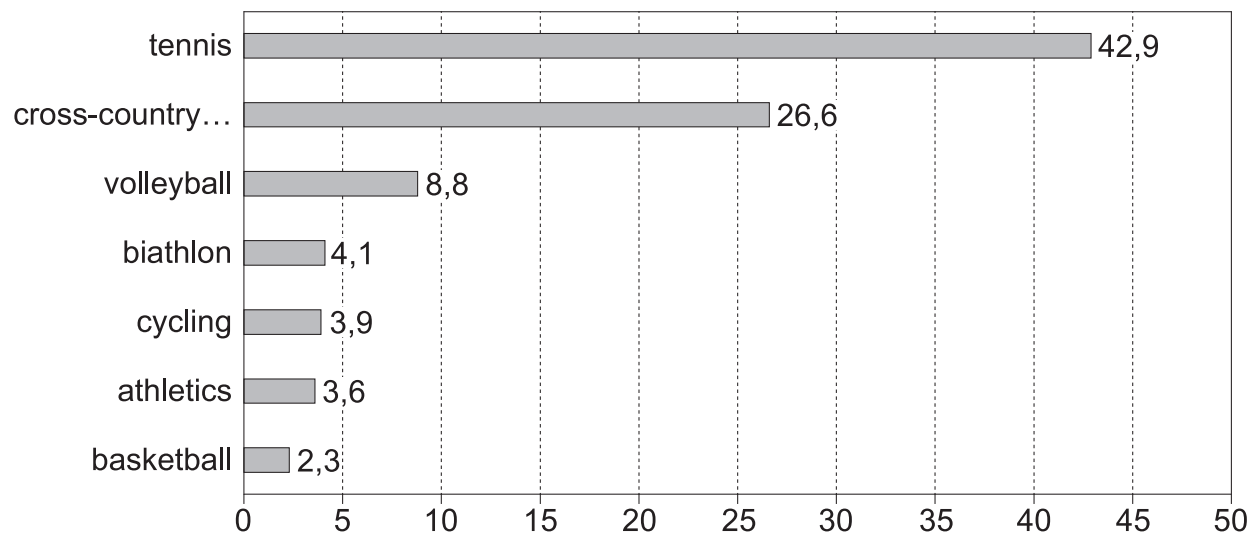

Source: Authors. 
firmed (Gee \& Leberman, 2011). The greatest number of articles was written on Justyna Kowalczyk - a cross-country skiing multi-medalist at the World Championships and the winner of the gold medal at the Olympic Games - and per cent of all articles on women's sports concerned Radwańska; 26.6 per cent of all the articles analyzed were written on Kowalczyk.

The lack of information on team sports must be pointed out. In GW, the results of the female Polish basketball, volleyball, and handball leagues were hardly ever covered. The only information presented concerned winning the Polish championship or the play-offs. In the case of male sports, information on the volleyball, basketball, and handball leagues were far more often published in the newspaper. Readers were also informed on the decisions in the first soccer league. Information on female team sports occurred almost exclusively in the context of the performances of national teams, which indicates that it was not the gender category that was a decisive reason for publishing a given material, but the fact that these teams were representing their country. The performances of Polish female athletes in the sports believed to be masculine ones were not covered as well.

The study also confirmed that mainly men were involved in writing media coverage on sports. Only 11 articles out of 2,997 were written by women (five journalists), while as many as 108 journalists participated in the process of developing sports material for GW. Not only are there many fewer female journalists among sports reporters than men, but they are also often assigned topics that are not directly related to sports competition (stadium construction, the design of the national soccer team logo, sponsoring the regatta, etc.). Only 5 articles written by women concerned sporting events directly (speedway racing), while the other 6 were classified as gender neutral. Moreover, the sex of experts interviewed for the articles published on the sports pages of GW was studied: there were 94 percent male and 6 percent female as the experts published on the sports page.

Study results - qualitative analysis of women's sports

In the articles on women's sports, attention was often drawn to the athletes' physical appearance. In some cases this was due to the sports disciplines and their chances for success in that particular sport. In the materials concerning Agnieszka Radwańska, readers would often encounter descriptions stating that she lacks extensive musculature, that she is small and quite short in comparison to other players. These physical characteristics were juxtaposed with her playing style (finesse, based on technique) and the necessity of withstanding onslaughts from her opponents. The articles, however, also included comments on the contestants' beauty, which in no way related to their sports activity. Sportswomen were described as "blonde beauties," "smiling beautifully," or "long-legged." Especially in the case of female tennis players, not only were their clothes on the court mentioned, but their party outfits were often mentioned as well: 
With a bright smile on her face, Radwańska attended a party at the Kensington Roof Gardens in western London, organized this weekend for the world's top female tennis players by the WTA and billionaire Richard Branson. Photos published on the official WTA website show Radwańska in a stunning dress engaged in a cheerful conversation with, among others, Serena Williams, who is dressed with matching flair ('Kubot targets Nadal', 21/06/2010).

A blonde beauty fond of posing for photos, not necessarily in full skiing gear (about Lindsey Vonn) ('Tigers prefer blondes', 21/03/2013).

Such descriptions must be considered as clearly sexist and support the belief that women's most important asset is their beauty. In GW, a changing trend emphasizing sexuality in the appearance of female athletes was observed. It was used as a deliberate marketing strategy and was based on an understanding that male sports fans are more interested in the appearance of women than in the results of their competition. Such a way of commenting on the behavior of fans may be regarded as explicitly marginalizing women's sports. Their value was reduced to the physical appearance of female athletes. A common tactic, apart from emphasizing the athletic build of sportswomen, was to describe their femininity through highlighting their nice smile, clothes, or features stereotypically associated with femininity. Such a comment may also be assessed as 'traditional' in the sense that women's athleticism and musculature are not considered to be a standard worth achieving, and they need to be balanced with other features recognized as more feminine.

The private relationships of female athletes were often elaborated on in the articles. Their relationships with their partners, including their wedding or divorce plans were emphasized. Very often these remarks on their relationships with men had no connection at all with the content of the articles. It also happened that references to the private relationships of tennis players were reprints from other newspapers. Such a quoting method allowed the publishers to give the impression that it was not their newspaper that was dealing with issues of minor importance, but rather they were only providing coverage on the most frequent stories taken from foreign press sources. Emphasizing the heterosexuality of female players often went hand in hand with describing their beauty. This may indicate the continuing trend to associate 'true' femininity with heterosexuality.

(...) she recently divorced Thomas Vonn, her coach and manager for many years. Apparently, she could not stand him trying to control every minute of her life. In an interview in People, she admitted that she suffered from severe depression; sometimes, she could not bring herself to get out of bed (about Lindsey Vonn) ('Golf and the neighborhood’, 21/03/2013).

She was able to rise again thanks to support from her new coach, Patrick Mouratoglou, owner of the famous academy, who had worked with many French sportspersons in the past. He started going with Serena for tournaments after her defeat in Paris last year. In winter, he took her to Mauritius, where they worked on her serves, forehands and self-confidence in peace and quiet (...). Last autumn, they were caught standing in a tender embrace. Serious newspapers and the 
couple themselves have not raised the subject. We only know that the American has lately been spending more time in Paris, where she owns an apartment and is learning French ('Nadal's eighth heaven. Serena's rendezvous after 11 years', 10/06/2013).

In the analyzed material, the issue of references to the stereotypical image of femininity based on inaction, passivity, or emotionality is a nuanced one. There were articles analyzed in which an 'excessive' display of emotions, poor mental structure, a lack of determination, or buoyancy were described. These were the features that were believed to be the causes of failure, but this observation was not a rule. In spite of what connotations arise from descriptions concerning their physical appearance, such characterizations were parallel to portrayals of the strength, endurance, and athleticism of female athletes. This situation, when applied to women's participation in sports, is stereotypically considered as feminine. In interviews with female athletes published in GW, one may see the tactics of complementing their beauty, asking them about their clothing choices, or about the ways in which they spend their free time. Agnieszka Radwańska was asked about pedicures, shopping, and her social calendar before tournaments; Justyna Kowalczyk - about the ways of maintaining her beauty:

During the awards ceremony, the Pole cried, struggling to speak. She thanked the public, saying that Serena deserved the title, and promised that this was not the end yet ('Polish tennis player's great success', 09/07/2012).

Are you a shopaholic? How many pairs of shoes do you own? Fifty, give or take.

Marriage and deep love only after you end your career, or will you pack your fiancé in your luggage and take him along with you?

How do you spend your free time during tournaments? Are you planning what you are going to do once you end your career? A hotel network, real estate development, collecting pieces of art...

Maybe you will open a manicure salon? Other tennis players say you are a master at giving manicures. The thing is I, as a man, do not really know what that means. Do you sometimes give other tennis players manicures?

You earn several million dollars every year. Are you a good investor? (Fingernails are a complicated matter', an interview with Agnieszka Radwańska, 22/04/2013).

In turn, athletes participating in sports considered to be masculine were asked about their non-sport roles. In interviews with a female boxer, ice hockey player, or triathlon contestant questions were asked about how to cope in a male sport, about their reasons for taking up such a sport, and about their plans for starting a family. Normally, journalists also asked whether their parents or partners approved of their participating in a sport regarded as masculine. Such a question suggests that female athletes are not self-reliant and need supervision from their relatives and friends. A similar impression is given by - frequently seen in sports 
articles - the discussion of relationships between female athletes and their parents (particularly the fathers of Radwańska and Vonn). This gives the impression that the players are not adults, but instead teenage girls that need care and supervision. In some cases, the language used by journalists was also infantilizing. Female athletes were called "girls," or they were mentioned in the texts only by their first name:

Agnieszka vs. Karolina, or a grand match in California (19/03/2010, about Agnieszka Radwańska and Karolina Woźniacka); She wants to thrash Serena (21/01/2013, about Sloane Stephens); Justyna running to win the gold (27/02/2013, about Justyna Kowalczyk).

This way of addressing them may be suggestive of a lack of distance and treatment of these female athletes as children instead of independent adults. At the same time, use of martial metaphors and descriptions of strength and athleticism in retelling accounts of sporting duels attracted particular attention:

Radwańska's struggle with the Williams sisters was like infantry going against tanks. With difficulty, the more delicate and physically weak Pole put a scratch on the armor of her champion rivals, who have been dominating tennis in recent years ('Radwańska toppled Venus', 29/03/2013).

The last category of coding concerned the ways of relating to the failures and successes of female athletes. As previously described in the quantitative analysis section, if an article is to be about women, those women need to be real stars and to be quite successful in their field. GW often delivered coverage on the successes of Kowalczyk and Radwańska; however, descriptions of failures were also frequent. In particular, volleyball was described from the perspective of matches lost. Defeats were characterized as "disasters," "seppuku," and "catastrophes":

The Polish female volleyball team lost after a dramatic five-set battle, perhaps burying their chances for their first world championship medal in nearly 40 years ('Seppuku done the Polish way', $30 / 10 / 2010)$.

Information on sports other than tennis, cross-country skiing, or volleyball was scarce, and when it was published, it turned out to be accounts of unsuccessful performances. In an article on a female figure skater, her performance was described as "shameful":

Anna Jurkiewicz placed last (30) in the obligatory singles program. The 26-year-old Pole performed disastrously, failing to pull off any of the planned jumps. "Shame!", said the Eurosport commentators ('A Pole’s shameful performance', 25/02/2010).

Similarly, the performances of female biathlonists were described as repeated failures due to their lack of mental toughness and nervous attitudes. A limited number of sports accounts on women, combined with frequent negative comments, give the impression that women's sports are an inferior category of sports. 


\section{DISCUSSION}

The results of the analysis of the content of the media coverage are generally consistent with previous studies. In the quantitative analysis, attention is drawn to the significant underrepresentation of coverage on women's sports. The only study on sports communications thus far - carried out in Poland in 2011 - reported that 9 per cent of space in the press was dedicated to women (Jakubowska, 2013). This is due to the fact that sports are continuously perceived as a male endeavor. However, attention should be given to the percentage increase in the number of articles describing women's sports in the years 2012 and 2013. While the 2012 Olympics and Radwańska's Wimbledon success might have caused the increase, no such explanation can be found for 2013. Therefore, further research is needed to verify a potential change in the trend. What is more, further research on sports media coverage should be done, which is not limited to the press, or press research should be expanded with some other titles.

The vast majority of authors of sports articles are men, and they are frequently experts on the subject. Such a situation reinforces male hegemony in sport and hinders its recognition as a female pursuit. This remains the case despite the growing number of female participants in sports. The study also confirmed that the most eagerly discussed news on women's sports concerns areas stereotypically considered as feminine or neutral (Koivula, 2001). The same applied to the articles on men's sports; a vast majority of articles dealt with contact and team sports. In the qualitative section it was proved that GW depicted female athletes following the techniques specified by Wensing and Bruce (2003). Their beauty and out-of-sport roles were focused on, and they were described in an infantilizing manner. Such depictions comply with Connell's concept of emphasized femininity. It also supports the way of looking at female contestants as 'the others' in sports. It should be noted that the results of the study confirm Connell's belief that masculinity and femininity are mutually related. The press coverage in GW constructs femininity and masculinity in sport in their traditional sense. The results confirm Kane's (2013) conviction that women's sports in the media are either ignored (results of quantitative analysis) or described employing traditional and stereotypical narration (results of qualitative analysis).

\section{CONCLUSIONS}

The results presented in the study of the sports press coverage of men and women demonstrate that information in the media is gender-determined. The analysis of the material allows for the conclusion that the construction of an article in GW is largely determined by the sex of a given athlete. The outcomes presented do not demonstrate any positive differences from the perspective of equal rights for women in sports as compared to the results shown in the literature review. Such a state of 
affairs reinforces the inferiority of female athletes and makes it harder to change the way women's sports are perceived. Women's sports have been presented according to prevailing trends, which obviously makes it harder to gain recognition of the readers. Taking into account the absence of female sports' journalists in the medium analyzed, it is possible that their greater number could change the way women's sports are presented. Identifying sport as an institution shaped by men and for men would also enable seeing the position of women's sports as less significant compared to their male counterparts. It should be borne in mind that it is not only media coverage on women's sports that shows marginalization of female athletes' achievements. Female coaches, sports journalists or personnel of sports organizations are also seen as incongruous with sport (Jakubowska 2014). That being so, the problem of media coverage on women's sports should be analyzed from the perspective of the androcentric structure of this institution.

\section{REFERENCES}

Angelini, J. R., MacArthur, P. J., \& Billings, A.C. (2012). What's the gendered story? Vancouver's prime time olympic glory on NBC. Journal of Broadcasting \& Electronic Media, 56, pp. 261279.

Billings, A. C., Brown, Ch. L., Crout, J. H. III, McKenna, K., Rice, B., Timanus, M., \& Ziegler, J. (2008). The games through the NBC lens: Gender, ethnic, and national equity in the 2006 Torino Winter Olympics. Journal of Broadcasting \& Electronic Media, 52, pp. 215-230.

Billings, A. C., \& Young, B. D. (2015). Comparing flagship news programs women's sport coverage in ESPN's Sports Center and FOX Sports 1's FOX Sports Live. Electronic News, 9, pp. 2-16.

Bishop, R. (2003). Missing in action. Feature coverage of women's sport in Sport Illustrated. Journal of Sport And Social Issues, 27, pp. 184-194.

Capranica, L., Minganti, C., Billat, V., Hanghoj, S., Piacentini, M. F., \& Cumps, E. (2005). Newspaper coverage of women's sport during the 2000 Sydney Olympic Games: Belgium, Denmark, France and Italy. Research Quarterly for Exercise and Sport, 76, pp. 212-223.

Connell, R. W. (1998). Gender and Power, Society, The Person and Sexual Politics. Cambridge: Polity Press.

Connell, R. (2001). Masculinities. Cambridge: Polity Press.

Connell, R. (2013). Socjologia ptci [Gender in world perspective], 2nd edition, Warsaw: PWN.

Cooky, Ch., Messner, M. A., \& Hextrum, R. A. (2013). Women play sport, but not on TV: A longitudinal study of televised news media, Communication \& Sport, pp. 1-28.

Cooky, Ch., Messner, M. A., \& Musto, M. (2015). “It's dude time!”: A quarter century of excluding women's sports in televised news and highlights shows, Communication \& Sport, 3, pp. 261-287.

Cronk, A. \& Theberge, N. (1994). Work routines in newspaper sport departments and the coverage of women's sports. In: S. Birrell, Ch. L. Cole (eds.), Women, Sport and Culture. Champaign: Human Kinetics, pp. 289-298.

Daddario, G. (1994). Chilly scenes of the 1992 Winter Games: The mass media and the marginalization of female athletes. Sociology of Sport Journal, 2, pp. 275-288.

Daniels, E., \& Wartena, H. (2011). Athlete or sex symbol: What boys think of media representations of female athletes. Sex Roles, 65, pp. 566-579.

Ducan, M., Messner, M., Williams, L., Jensen, K., \& Wilson, W. (1994). Gender stereotyping in televised sports. In: S. Birrell, Ch. Cole (eds.), Women, Sport and Culture. Champaign: Human Kinetics, pp. 249-272. 
Gee, B. L., \& Leberman, S. I. (2011). Sports media decision making in France: How they choose what to get to see and read. International Journal of Sport Communication, 4, pp. 321-343.

Giulianotti, R. (1999). Football: A Sociology of the Global Game. Cambridge: Polity.

Harris, J., \& Clayton, B. (2002). Femininity, masculinity, physicality and the English tabloid press. International Review for the Sociology of Sport, 37, pp. 397-413.

Hardin, M., Shain, S. (2005). Female sport journalist: Are we there yet? 'No.' Newspaper Research Journal, 26, pp. 22-35.

Ingen, C., \& Kovacs, N. (2012). Subverting the skirt: Female boxers' "troubling" uniforms, Feminist Media Studies, 12, pp. 460-463, DOI: 10.1080/14680777.2012.698091.

Jakubowska, H. (2013). Are women still the 'other sex': Gender and sport in the Polish mass media. Sport in Society: Cultures, Commerce, Media, Politics, 18, pp. 168-185.

Jakubowska, H. (2014). Gra ciałem. Praktyki i dyskursy różnicowania płci w sporcie [The Game of the Body. The Practices and Discourses of Gender Differentiation in Sport]. Warsaw: WN PWN.

Kane, M. J. (2013). The better sportswomen get, the more the media ignore them. Communication \& Sport, 1(3), pp. 231-236.

Kian, M. E. (2007). Gender in sports writing by the print media: An explanatory examination of writers' experiences and attitudes. The SMART Journal, 4, pp. 5-26.

Kian, M. E., \& Hardin, M. (2009). Framing of sport coverage based on the sex of sports writers: Female journalists counter the traditional gendering of media coverage. International Journal of Sport Communication, 2, pp. 185-204.

King, Ch. (2007). Media portrayals of male and female athletes. International Review for the Sociology of Sport Journal, 42, pp. 187-199.

Knight, J., \& Giuliano, T. (2001). He's a laker; She's a “looker": The consequences of gender-stereotypical portrayals of male and female athletes by the print media. Sex Roles, 45, pp. 217-229.

Kluczyńska, U. (2010). Konstruowanie relacji między płciami w sporcie. Analiza telewizyjnych wiadomości sportowych [Constructing the relations between gender in sports. The analysis of television sports news]. In: K. Slany, B. Kowalska, M. Ślusarczyk (eds.), Kalejdoskop Genderowy [Gender's kaleidoscope]. Cracow: WUJ. pp. 383-400.

Koivula, N. (2001). Perceived characteristics of sports categorized as gender-neutral, feminine and masculine. Journal of Sport Behavior, 24, pp. 377-393.

Martin, T. G., Suh, Y. I., Williams, A. S., Locey J., Ramirez, J. \& Alea, M. (2016). Comparative analysis of female and male coverage on ESPN's SportsCenter. Global Sport Business Journal, 4, pp. 14-24.

Messner, M. (1992), Power at Play: Sport and the Problem of Masculinity. Boston: Beacon Press.

Messner, M. A., \& Sabo, D. F. (1994). Sex, Violence and Power in Sport, Rethinking Masculinity. New York: Crossing Press.

Messner, M. A. (1998). Sport and men domination: The female athlete as contested ideological terrain. Sociology of Sport Journal, 5, pp. 197-211.

Messner, M., \& Cooky, C. (2010). Gender in Televised Sports: News and Highlights Shows, 1989-2010. University of Southern California Center for Feminist Research, http://dornsifecms.usc.edu/ assets/sites/80/docs/tvsports.pdf.

O’Neill, D., \& Mulready, M. (2014). The invisible woman?. Journalism Practice. DOI: $10.1080 / 17512786.2014 .965925$.

Pedersen, P. M. (2002). Examining equity in newspaper photographs: A content analysis of the print media photographic coverage of interscholastic athletics. International Review for the Sociology of Sport, 37, pp. 303-318.

Riemer, B., \& Visio, M. (2003). Gender typing of sports: An investigation of metheny's classification. Research Quarterly for Exercise and Sport, 74, pp. 193-204.

Sailors, P., Teetzel, S. \& Weaving, Ch. (2012). No net gain: a critique of media representations of women's Olympic beach volleyball. Feminist Media Studies, 12, pp. 468-472. 
Sherry, E., Osborne, A., \& Nicholson, M. (2015). Images of sports women: A review. Sex Roles, 74, pp. 299-309.

Tuchman, G. (1979). Women's depiction by the mass media. Signs: journal of women. Culture and Society, 3, pp. 528-524.

Wachs, F. L. (2006). "Throw like a girl” doesn't mean what it used to: Research on gender, language and power. In: L. Fuller (eds.), Sport, Rhetoric and Gender. Historical Perspectives and Media Representation. New York: Palgrave MacMillian, pp. 43-54.

Whitson, D. (1989). Sport in the social construction of masculinity. In: M. Messner, D. F. Sabo (eds.), Sport, Men and the Gender Order. Champaign: Human Kinetics.

Wensing, E., \& Bruce, T. (2003). Bending the rules. Media representations of gender during an international sporting events. International Review for The Sociology of Sport, 38, pp. 387-396.

Vincent, J. (2000). Game, sex, and match: The construction of gender in British newspaper coverage of the 2000 Wimbledon Championships. Sociology of Sport Journal, 21, pp. 435-456.

Vincent, J., Imwold, Ch., Masemann, V., \& Johnson, J. (2002). A comparison of selected serious and popular British, Canadian, and United States newspaper coverage of female and male athletes competing in the Centennial Olympic Games. International Review for the Sociology of Sport, 37, pp. 319-335.

Vincent, J. (2004). Game, sex, and match: The construction of gender in British newspaper coverage of the 2000 Wimbledon Championships. Sociology of Sport Journal, 21, pp. 435-456.

von der Lippe, G. (2002), Media image. Sport, gender and national identities in five European countries. International Review for the Sociology of Sport, 37(3-4), pp. 371-395.

\section{ACKNOWLEDGEMENTS}

We extend our thanks to Professor Michał Lenartowicz for his invaluable substantive guidelines that have greatly enriched this research project.

The study was conducted as part of the research project DM-35 at the Józef Piłsudski University of Physical Education in Warsaw. 